$11-1-2020$

\title{
Gender integration in social and behavior change
}

\author{
Debora B. Freitas Lopez \\ Sanyukta Mathur \\ Population Council \\ Haley Brightman \\ Kathryn Berryman \\ Kamden Hoffmann \\ Population Council
}

Follow this and additional works at: https://knowledgecommons.popcouncil.org/departments_sbsr-pgy

Part of the Health Communication Commons, and the Public Health Commons

How does access to this work benefit you? Let us know!

\section{Recommended Citation}

Freitas Lopez, Debora B., Sanyukta Mathur, Haley Brightman, Kathryn Berryman, and Kamden Hoffmann. 2020. "Gender integration in social and behavior change," Breakthrough RESEARCH Scoping Report. Washington, DC: Population Council. 
SCOPING REPORT

\section{Gender Integration in Social and Behavior Change}

NOVEMBER 2020

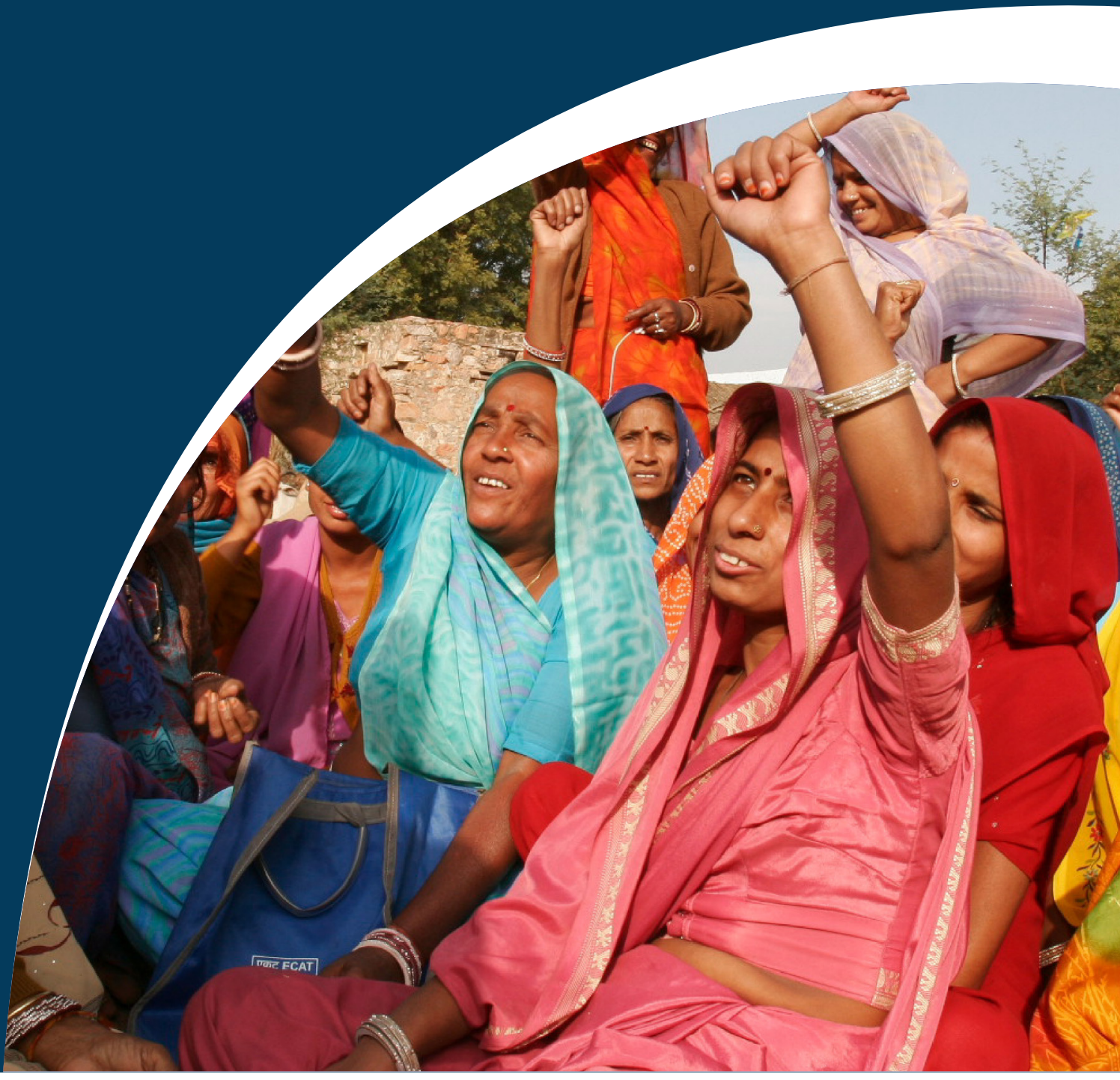

(E) USAID 


\section{Acknowledgments}

The authors would like to thank Arti M. Srinivasan and Maria V. Diaz for their efforts in conducting the initial literature review and drafting an earlier version of this scoping report. We would also like to thank colleagues at USAID (Hope Hempstone, Angie Brasington, Afeefa Abdur-Rahman, Joan Kraft, and Lindsay Swisher), URC (Liz Nugent, Patricia O'Connor), Breakthrough RESEARCH (Laura Reichenbach), Population Council (Julie Pulerwitz) and CORE Group (Lisa Hilmi and members of the Social and Behavior Change Working Group), who provided input for the report.

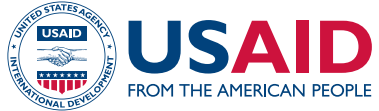

Breakthrough RESEARCH is made possible by the generous support of the American people through the United States Agency for International Development (USAID) under the terms of cooperative agreement no. AID-OAA-A-17-00018. The contents of this document are the sole responsibility of the Breakthrough RESEARCH and Population Council and do not necessarily reflect the views of USAID or the United States Government.

\section{POPULATION COUNCIL \\ Ideas. Evidence. Impact.}

The Population Council confronts critical health and development issuesfrom stopping the spread of HIV to improving reproductive health and ensuring that young people lead full and productive lives. Through biomedical, social science and public health research in about 50 countries, the Council works with our partners to deliver solutions that lead to more effective policies, programs, and technologies to improve lives worldwide. Established in 1952 and headquartered in New York, the Council is a nongovernmental, nonprofit organization with an international board of trustees.

\section{Breakthrough
RESEARCH
FOR SOCOAL \& BEAAVIOO CHANGE}

Breakthrough RESEARCH catalyzes social and behavior change (SBC) by conducting state-of-the-art research and evaluation and promoting evidence-based solutions to improve health and development programs around the world. Breakthrough RESEARCH is a consortium led by the Population Council in partnership with Avenir Health, ideas42, Institute for Reproductive Health at Georgetown University, Population Reference Bureau, and Tulane University.

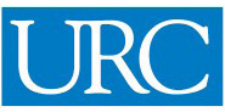

From its beginning in 1965, URC has combined the idealism of the era and the rigor of research with the pragmatism necessary to achieve results. Today, URC is a thought leader in the development and implementation of best practices to improve the quality and impact of health and social services and systems. URC focuses on making improvements in such areas as: maternal, neonatal, and child health care; HIV/AIDS, TB, and malaria prevention and treatment; global health security; and food and nutrition support. Our expertise in system strengthening and improvement, research and evaluation, implementation science, social and behavior change, and gender and social inclusion allows us to develop and implement sustainable, evidence-based solutions for a wide range of challenges. By remaining true to our mission, URC is poised to support the well-being and resiliency of families and their communities for the next 50 years, and beyond.
(C)2020 The Population Council. All rights reserved.

Cover photo by CUSAID/India

\section{Suggested Citation}

Freitas Lopez, Debora B., Sanyukta Mathur, Haley Brightman, Kathryn Berryman, and Kamden Hoffmann. 2020. "Gender integration in social and behavior change," Breakthrough RESEARCH Scoping Report. Washington, DC: Population Council.

\section{Contact}

4301 Connecticut Avenue NW, Suite 280 | Washington, DC 20008 +1202 2379400 | BreakthroughResearch@popcouncil.org breakthroughactionandresearch.org 


\title{
Gender Integration in \\ Social and Behavior Change
}

\author{
Debora B. Freitas Lopez ${ }^{1}$ Sanyukta Mathur ${ }^{2} \quad$ Haley Brightman ${ }^{1}$ \\ Kathryn Berryman ${ }^{1} \quad$ Kamden Hoffmann ${ }^{2}$
}

${ }^{1}$ University Research Co. LLC (URC)

${ }^{2}$ Population Council 


\section{Acronyms}

$\mathrm{FGM} / \mathrm{C}$

GBV

GRIDES

HIV

IGWG

SBC

SDG

$\mathrm{SRH}$

USAID
Female genital mutilation/cutting

Gender-based violence

Risk Management and Climate Change Adaptation Networks

Human immunodeficiency virus

Interagency Gender Working Group

Social and behavior change

United Nations Sustainable Development Goals

Sexual and reproductive health

United States Agency for International Development 


\section{Table of Contents}

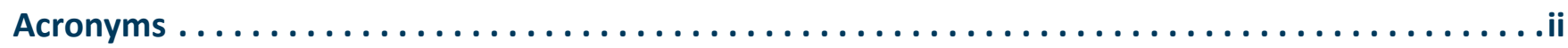

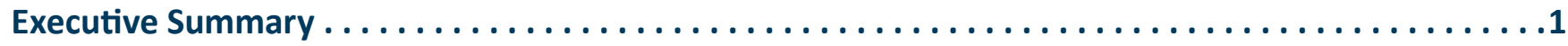

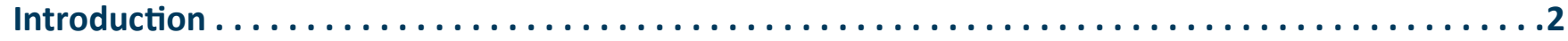

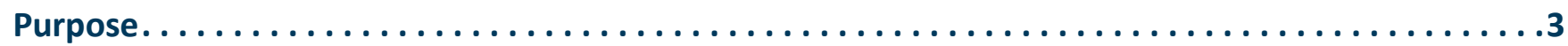

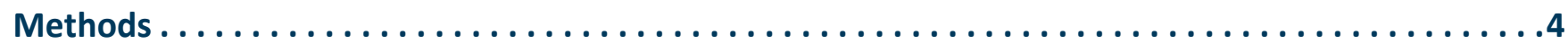

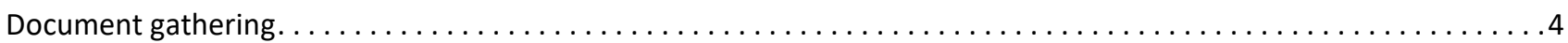

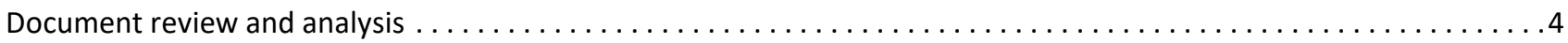

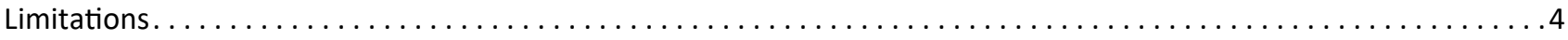

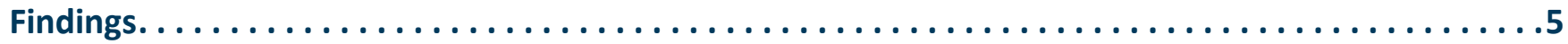

1: Use a gender-lens throughout the SBC program cycle to improve outcomes $\ldots \ldots \ldots \ldots \ldots \ldots \ldots \ldots \ldots \ldots \ldots \ldots \ldots \ldots \ldots$

2: Synchronize gender strategies to ensure inclusion of men and women, and boys and girls. . . . . . . . . 6

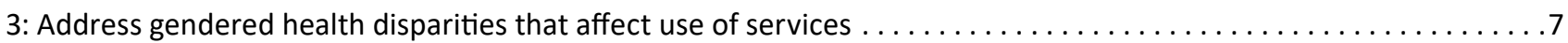

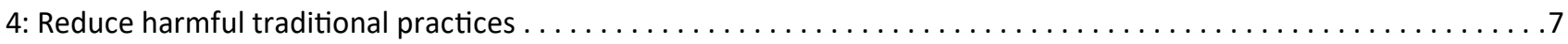

5: Ensure community involvement and accountability for promotion of gender equality $\ldots \ldots \ldots \ldots \ldots$

6: Consider gender dimensions during emergency preparedness and response $\ldots \ldots \ldots \ldots \ldots$

7: Account for the intersecting gendered vulnerabilities that influence health and development outcomes ........10

8: Build organizational capacity and systems for gender integration using a continuous learning approach ........10

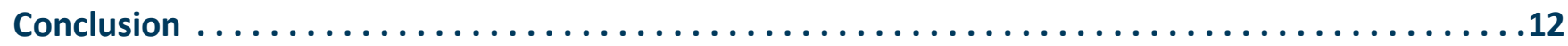

Appendix 1: Phases 1 and 2 Key Search Terms..............................

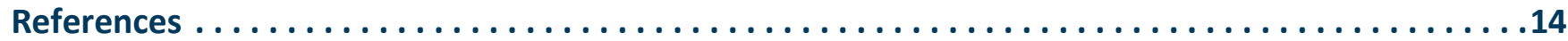


IV GENDER INTEGRATION IN SBC 


\section{Executive Summary}

Social and behavior change (SBC) programs and interventions across health and non-health sectors seek to shift behaviors of individuals, as well as the norms that underpin them. These programs include a range of activities that address key determinants (e.g., knowledge and attitudes), critical to ensuring that target populations, including the most marginalized, can demand and access needed resources and services that can lead to behavior change and improvements in their own and their family's health and development. ${ }^{1} \mathrm{~A}$ range of social and structural factors, such as unequal power in sexual relationships; unbalanced agency in household decision-making; and disproportionate economic, educational, and legal resources, systematically disadvantage women and girls, and can negatively affect men and boys too. ${ }^{2}$ As such, SBC programs are uniquely placed to make a difference in achieving gender transformative goals.

This document is a review of recent SBC-focused program literature $(\mathrm{N}=98)$ that highlight integration of gender considerations into health and non-health SBC interventions. The review revealed eight promising practices as follows:

1. Use a gender lens throughout the SBC program cycle to improve outcomes.

2. Synchronize gender strategies to ensure inclusion of men and women, and boys and girls.

3. Address gendered health disparities that affect use of services.

4. Reduce harmful traditional practices.

5. Ensure community involvement and accountability for promotion of gender equality.

6. Consider gender dimensions during emergency preparedness and response.

7. Account for the intersecting gendered vulnerabilities that influence health and development outcomes.

8. Build organizational capacity and systems for gender integration using a continuous learning approach.
These gender integration practices were found to be operationalized at different levels of the Socio-Ecological Model for Change and were mutually reinforcing. When employed, these practices can strengthen gender integration and mainstreaming efforts in SBC programming. Additional investments and coordination towards efforts that directly aim to mainstream and integrate gender into SBC health and development approaches are warranted. 


\section{Introduction}

Integrating gender into SBC programs and interventions is key to promoting gender equality and achieving intended outcomes among men and women, and boys and girls. A range of social and structural factors, such as limited power in sexual relationships, limited agency in household decision-making, and insufficient economic, educational, and legal support, systematically disadvantage women and girls. ${ }^{2}$ Integrating gender into development programs and policies can promote women and girls to become equal partners and agents of change with men and boys. Achieving the United Nations Sustainable Development Goals (SDGs) across sectors will be difficult without integrating gender perspectives into health and non-health programming. ${ }^{2,3}$

The United States Agency for International Development (USAID) Interagency Gender Working Group (IGWG) highlights the importance of using a gender lens for developing project approaches and understanding the steps along the Gender Integration Continuum (moving away from gender exploitative to gender transformative approaches). ${ }^{4}$ According to this framework (see Figure 1), ${ }^{5}$ gender exploitative approaches take advantage of rigid gender norms and power imbalances to achieve program objectives. These approaches can undermine the program goals and objectives. Gender accommodating approaches seek to limit any harmful impact on gender relations. Gender transformative approaches encourage critical awareness of gender roles and norms, empowering women and engaging men, and examining, challenging, and addressing the imbalance of power and inequitable distribution of duties or resources between men and women as well as across all gender identities. By integrating gender into SBC approaches, messages and interventions can be more effective, stimulate gender equity, and improve health and development outcomes.

Despite progress made to integrate gender into SBC approaches and programming, not enough is known about the gender integration processes used by SBC programs across health and non-health sectors. Additionally, the process of incorporating a gender lens at the organizational level (gender mainstreaming) has received inadequate attention. Further, gender integration is often seen as a synonym for "adding women and girls" or "adding men and boys" rather than a balanced gender synchronization approach.

Gender synchronization means working
with men and women, boys and girls,
in an intentional and mutually reinforcing way
that challenges gender norms, catalyzes the
achievement of gender equality, and improves
health."6

\section{FIGURE 1 USAID IGWG GENDER INTEGRATION CONTINUUM}

\section{Gender Integration Continuum}

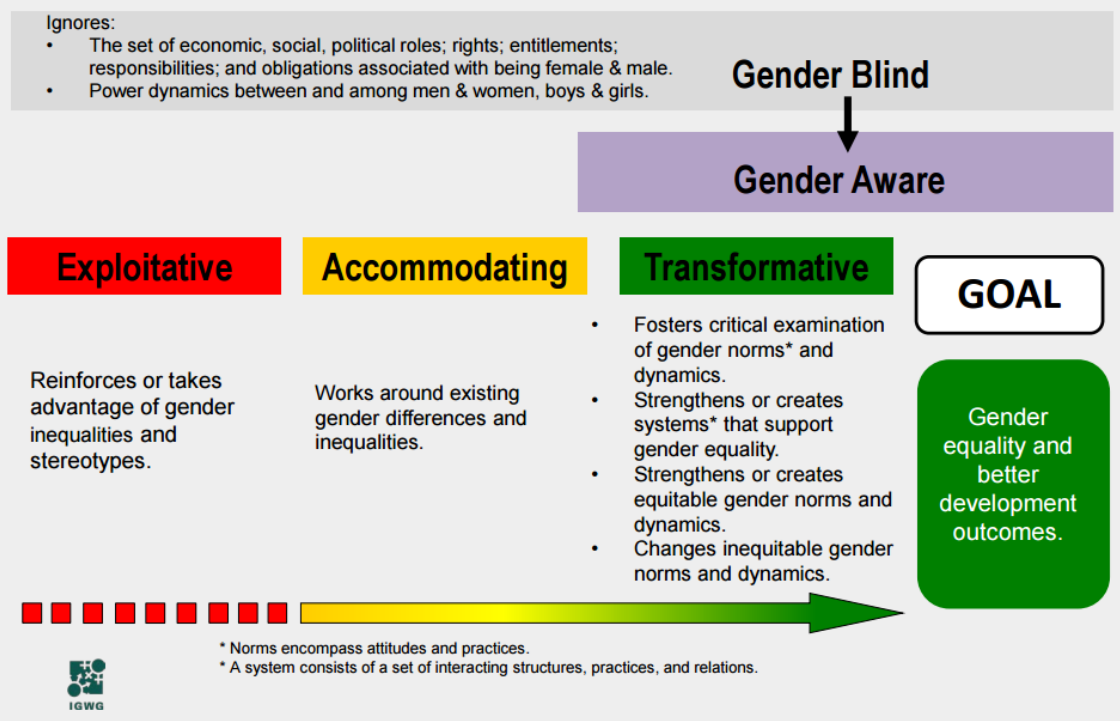




\section{Purpose}

The purpose of this scoping report was to gather evidence on gender integration in SBC programming across health and non-health sectors. This report shares promising practices with SBC partners to strengthen gender integration efforts in SBC programming.

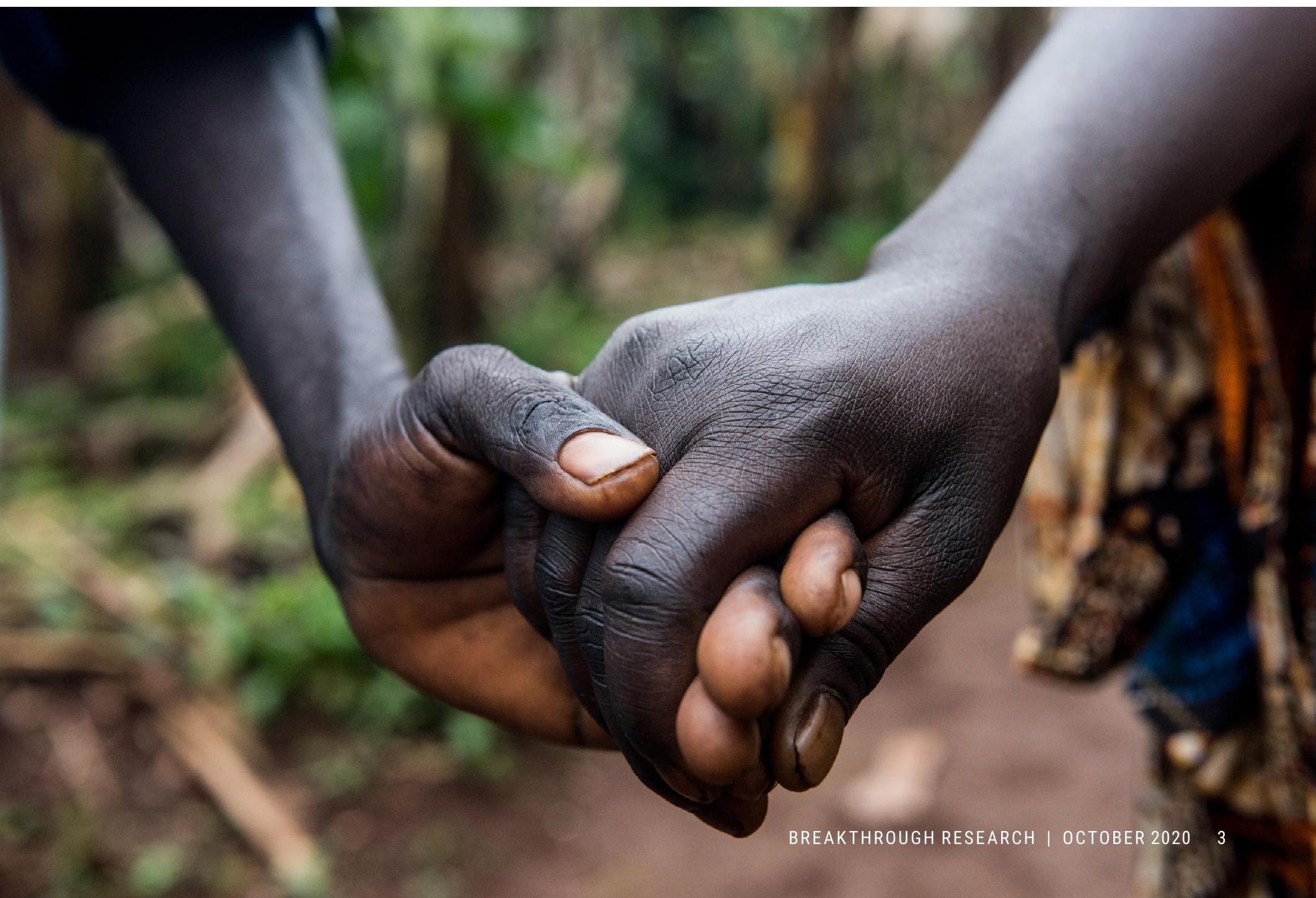




\section{Methods}

\section{Document gathering}

Two phases of reviews captured documents spanning 2005-2019. Key terms used for the document searches during both phases are noted in Appendix 1. A broad set of search terms was used to capture mentions of gender and gender integration in the health and nonhealth focused literature. During the first phase, a request for gray literature, articles, and reports from members of the CORE Group was initiated via the Social and Behavior Change Working Group listserv in February 2016. Additionally, a search was conducted through the Development Experience Clearinghouse, Popline, PubMed, and Google Scholar of articles or reports published from 2005 to 2015. The second phase included a scan of literature via Google Scholar and PubMed search of articles, reports, and other documents from 2016 to 2019, which included documents from the Development Experience Clearinghouse. Excluded literature included documents not published in English, documents that did not include "gender mainstreaming" or "gender integration" as well as another keyword term, and articles that discussed study designs, books, and opinion pieces. If these elements were included, the full document was reviewed.

\section{Document review and analysis}

An initial review of each document assessed if it presented evidence or findings of programmatic interventions or evidence related to gender integration and included an SBC perspective (e.g., programs addressing knowledge, attitudes, practices, and norms). If these elements were included, the full document was reviewed in detail and gender integration practices catalogued. After review of all the documents, prominent practices were extracted, and examples of gender integration and outcomes synthesized. The gender integration in SBC practices included in this scoping review aimed to improve individual or collective behaviors by addressing knowledge, attitudes, norms, and other social or structural drivers of gender inequity. Eight practices emerged as promising for inclusion in SBC programming to strengthen gender integration and ultimately to contribute to shifting norms and reducing gender inequality.

\section{Limitations}

A scoping review was conducted instead of a systematic review with the aim of rapidly identifying emerging practices for gender integration in health and non-health SBC programs. While attempts were made to conduct an expansive search, some peer-reviewed literature and program resources may have been left out. Different combinations of key terms might have yielded more and different sets of literature. Subsequent systematic reviews may be warranted and should consider issues related to gender identity and the quality of the evidence generated and presented about gender integration in SBC programming. Broadening to include non-English language resources may provide additional insights not currently captured in this report.

Sulekha.com (Cropped; CC BY-NC 2.0)

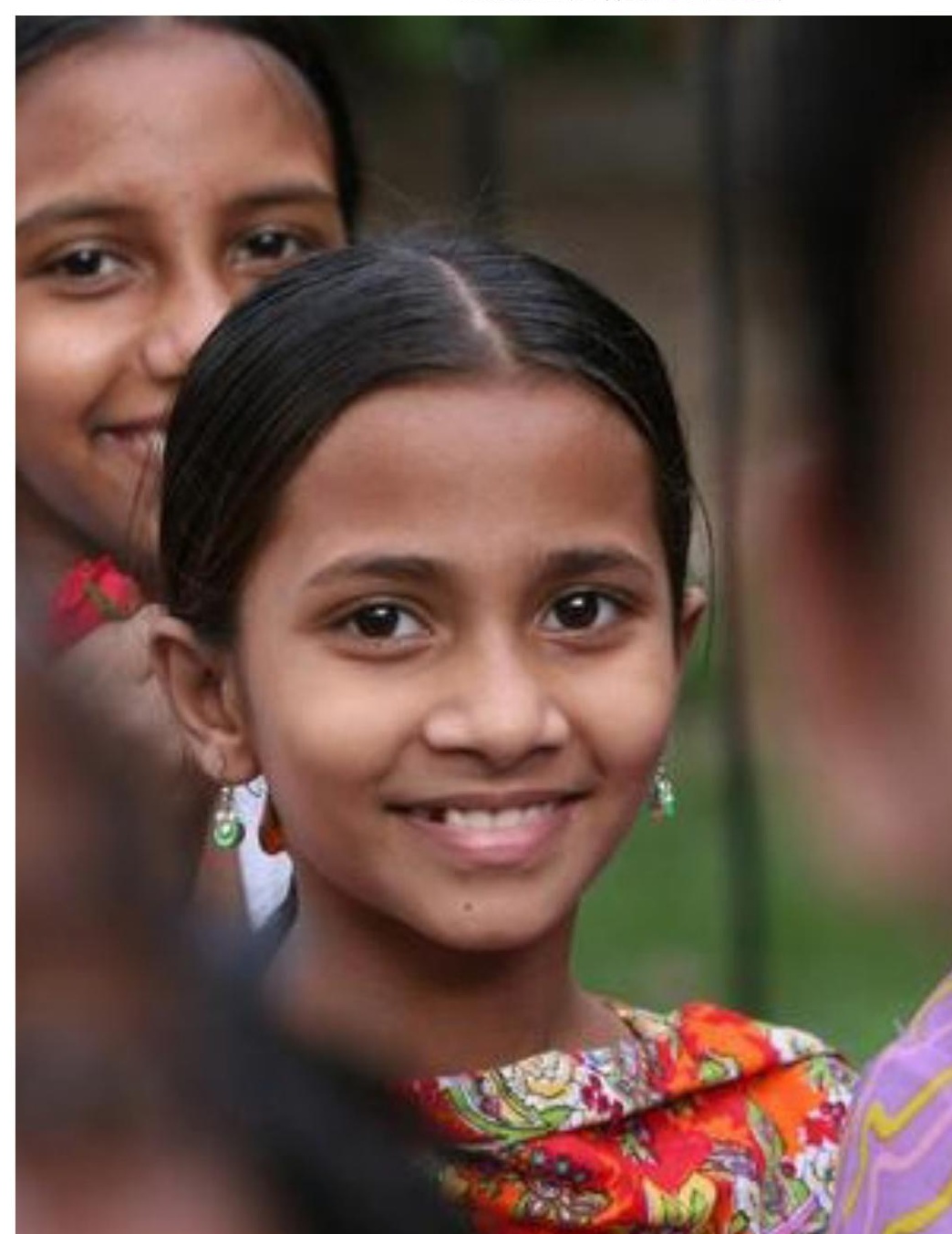




\section{Findings}

A total of 98 documents were reviewed for this scoping report. Documents were from a range of technical areas and nearly 70 percent of the documents represented more than one technical area: policy development $(n=20)$; agriculture $(n=17)$; climate adaptation $(n=13)$; human immunodeficiency virus (HIV) ( $n=12)$; governance ( $n=11)$; sexual and reproductive health (SRH) $(n=11)$; gender-based violence (GBV) ( $n=11)$; nutrition $(n=4)$; economic growth $(n=8)$; and international development $(n=2)$. For example, documents that discussed agriculture and program planning were counted in two categories as they provided data for both technical areas.

The practices synthesized below reflect gender integration across various socioecological levels-individual, community, organizational, and/or policy-level. The practices are not mutually exclusive, but rather were often mutually reinforcing and SBC programs often implemented multiple activities to achieve gender integration. The following is a summary of these eight promising practices and include illustrative examples of each.

\section{Use a gender-lens throughout the SBC program cycle to improve outcomes}

Gender needs to be considered throughout the SBC program cycle: assessment, planning, design, implementation, monitoring, evaluation, and learning. Limited attention to gender throughout the program cycle can unintentionally lead to gender-blind or gender-

exploitative interventions. ${ }^{7}$ For instance, a social marketing intervention in Bolivia intended to market "safe sex" to young men and women consisted of a television spot featuring a young man proudly explaining that he used a different color condom with each of his girlfriends. Though the intended message was to promote condom use and increase condom sales, the campaign reinforced social and cultural norms about masculinity defined by multiple sexual partnerships. ${ }^{7}$ In this case, the intended messages around partner communication and mutual decision-making around safer sexual practices may not have been communicated as effectively among the target populations. By using a gender-lens, SBC programs can identify and address gender differences, roles, and relationships and assess gender-related challenges and opportunities in program objectives and monitoring and evaluation indicators.

As a first step, gender analysis (Box 1) can facilitate application of a gender-lens into each stage of the program cycle. ${ }^{8}$ The next step, using findings from the gender analysis, is to design and implement SBC interventions to improve agency and capacity, shift gender norms and attitudes, and transform systems and structures,

\section{BOX 1: PROCESS OF GENDER ANALYSIS}

Gender analysis explores how gender relations affect a development problem. Applied within the SBC program lifecycle, gender analysis can be used to assess how gender relations affect programs, what can be done to affect them, and how programs affect gender relations. A gender analysis will typically examine the gender roles and norms; levels of power held in relationships, households, and communities; women and girls and men and boys' needs, constraints, and opportunities; and the impact of these differences throughout each person's lifecycle.

\section{Prerequisite resources:}

- Specialized expertise in gender issues and sector-specific technical expertise to conduct/use research

- Time to analyze the data

- Access to financial resources for new research

- Access to national data including gender statistics, findings from pilot projects, results from program monitoring and evaluation, and qualitative data generated through policy and academic research

\section{Illustrative tools:}

- Harvard Analytical Framework

- Moser Gender Planning Framework 
ensuring a space for a range of perspectives across all genders, not just the typically dominant men's perspectives. ${ }^{9}$ For example, a program aiming to reduce HIV/ AIDS vulnerability uses a participatory learning approach for engaging and empowering women and men to "build sexual health knowledge and reflect on behavioral motivations."10,11 The program's critical components include reflection on individual biases, discussion of local norms and traditions, and skills building around assertiveness and communication. At a minimum, routine data collection in SBC programs should disaggregate data by gender and age. However, equally important is the need to measure and monitor gender-related factors addressed in the intervention, such as gender roles, gender norm attitudes, GBV, and relationship power dynamics to refine and improve program outputs. Continuous generation of evidence around the transformation of underlying community-level social norms and institutional structures surrounding men and women, boys and girls, and other focus populations is often needed. Further, translating this evidence into policy and program adaptation requires a concerted effort to avoid gender-blind or gender-exploitative interventions. ${ }^{5}$ This could include strengthening capacity for evidence use among implementers and decision-makers; building rapid and responsive knowledge sharing mechanisms to make research directly available; and making findings understandable and accessible. ${ }^{12}$

\section{Synchronize gender strategies to ensure inclusion of men and women, and boys and girls}

Efforts at gender integration sometimes focus solely on reaching women and girls, or sometimes men and boys. However, engagement of women and girls and men and boys, including a full range of gender identities, in an intentional and mutually reinforcing way in SBC programs and interventions can assist in challenging restrictive gender norms, catalyzing the achievement of gender equality, and improving health and nonhealth outcomes. ${ }^{13-15}$ Social norms-both perceived and actual-often dictate what males and females should and should not do in a particular social context. For example, norms around women's mobility can limit their access to health resources. Conversely, norms around masculinity may discourage men's use of health services, resulting in increased poor health outcomes for men. ${ }^{16}$
An essential part of gender transformative approaches is the engagement of men and boys to challenge and reform gender norms. ${ }^{17}$ However, there is a delicate balance as efforts to engage men and boys should not further disempower and disengage women and girls. ${ }^{18}$ SBC practices that have attempted gender synchronization have generally tried to provide a platform for women and girls and men and boys to make decisions and evaluate gender norms together. In turn, they can advocate for gender equality and improve lives in their communities, foster meaningful discussion that challenges gender norms and expectations, and convene men and women, and boys and girls, to address these norms to change behaviors.

Achieving gender equity in SBC programs entails equal and quality engagement of men and women in formal and informal decision-making processes at multiple levels (e.g., national and local government, community structures, and intrahousehold level). ${ }^{13}$ Building spaces and opportunities through capacity building and other support mechanisms for women's participation in governance has shown to yield richer outcomes for the desired behaviors, including balanced participation in decision-making. In Ghana, women who were provided the opportunity to be leaders and actively participate in discussions on issues related to fisheries management led to more sustainable and economically beneficial fishing practices for the community. ${ }^{18}$ At the government level, women's participation as leaders and employees translates to better development outcomes for society at large and a shift in society norms related to gender roles. In India, for example, research on local councils found that the number of drinking water projects in areas with female-led councils was 62 percent higher than those with male-led councils. ${ }^{19}$ Successful approaches have engaged men and boys to help meet their own needs, as allies and partners, and as leaders and advocates in promoting gender equity. ${ }^{2,17}$ Fostering meaningful discussion among women and girls and men and boys, such as through new father's groups, ${ }^{20}$ can help to challenge and shift gender norms and expectations that affect both their own and their partners' lives. For example, a recent IGWG resource brings together recent best practices and lessons learned for male engagement across health areas and finds practical do's and don'ts for engaging men as clients, partners, and agents of change. ${ }^{17}$ This success of gender synchronized approaches has been particularly evident in programs that more explicitly address power differentials and inequalities. For example, in the United States, the "It's Your Place" campaign at the University 
of South Carolina used male and female perspectives and beliefs on sexual assault to target campus-wide awareness, responsibility, and norms to foster a culture of bystander intervention during a sexual assault. ${ }^{21}$ The university worked to shift norms by creating segmented messages and multiple/diverse communication channels to reach male and female students, including use of peer-to-peer facilitation and training, and university staff resources such as the university's amnesty policy and the Office of Victim Services confidential counseling services. Couple-based interventions may also be an approach to address social norms and gender stereotypes (e.g., those related to masculinity and femininity) that influence behavior and expectations related to SRH, GBV, fatherhood, and maternal and newborn health, among others, and to reflect critically on the current social construction of gender. ${ }^{22}$ However, SBC practitioners need to be mindful of potential unintended consequences, such as GBV, of programs that are attempting to shift gender and power dynamics. ${ }^{15}$

\section{Address gendered health disparities that affect use of services}

Gender disparities in access to, provision, and use of health services among women and girls and men and boys are persistent and influence a range of health and non-health outcomes. Health outcome differences between men and women may be due to biological or social factors. ${ }^{15}$ Gender inequalities can limit women's agency to be the decision maker about their health, their access to care, and access to resources needed for care. ${ }^{23}$ At the same time, gender norms may also influence men's access to and use of services based on their perceptions around the intended audience for the service. ${ }^{24}$ Integrating a lens on gender and health within SBC is necessary to address gender inequality and ensure positive health outcomes for all women and men, regardless of their age and gender identity. ${ }^{7}$ Many of these disparities are often exacerbated during times of crisis.

Interventions that mobilize formal and informal leaders and service providers to help shift perceptions and promote gender equality have shown promising results in improving health seeking behaviors of men and women, and boys and girls. For example, Project Hope for Mothers and Newborns in Mali integrated a social change approach with traditional maternal, newborn, and child health services to improve outcomes. The social change approach included couple counseling visits during pregnancy emphasizing husband support for their pregnant wives, sessions with extended family focusing on birth planning and support for the pregnant women, community dialogue to discuss challenges to safe pregnancy and childbirth, establishment of community committees to support community health workers in reaching pregnant women, and orientation of health workers to engage men in maternal, newborn, and child health services. ${ }^{25}$ Addressing provider biases, power dynamics, knowledge, and skills can support meaningful client-provider interaction and counseling among men and women, and boys and girls to achieve their health and well-being. ${ }^{26}$ For example, in 13 health facilities in Kenya, the Heshima project addressed individual and structural drivers of women experiencing mistreatment during facility-based childbirth. The project included interventions at the policy, facility, and community levels. Facility level interventions included values clarification and attitudes transformation workshops, mentorship for providers to improve quality of care in labor and delivery services, and establishment of quality improvement teams at each health facility, psychosocial support for health care providers, and invitations for communities to visit the facilities to dispel myths and misconceptions related to facility delivery. The project successfully shifted provider attitudes and health facility systems to ensure safe and respectful maternal care. ${ }^{27}$ Additionally, paying close attention to the different social and structural barriers (e.g. mobility, economic agency) that influence behavioral determinants, especially during times of conflict and emergency response, is critical. ${ }^{28}$

\section{Reduce harmful traditional practices}

In many settings, harmful traditional practices (e.g., child early and forced marriage and female genital mutilation/ cutting), GBV, and human trafficking disproportionately affect women and girls. Even when policies and legal frameworks exist to prevent these harmful practices, women and girls, particularly the most marginalized (e.g., women in conflict settings, women who have been trafficked, women engaged in sex work) continue to bear a heavy burden, which negatively impacts their health and other development outcomes. GBV, for example, affects nearly one in three women globally. Men's adherence to traditional ideas of masculinity, such as believing that "women are meant to only do household chores" or 
"men are the more dominant sex", has been associated with use of violence against their sexual partners, experience with sexually transmitted infections, breaking laws, and use of drugs. ${ }^{15}$ The influence of social norms can also be seen among women who learn to justify domestic violence. For example, in a study conducted in Ethiopia, 56 percent of the women agreed that their husbands were correct to beat and hit their spouses who fail to inform them before leaving home. ${ }^{29}$ In turn, women who experience GBV are more likely to suffer from other adverse health outcomes such as unintended pregnancy, unsafe abortions, maternal mortality, depression, child death, and sexually transmitted infections/HIV. ${ }^{30}$ Harmful traditional practices also negatively impact broader development outcomes. For instance, girls who marry early (before age 18) are less likely to complete schooling and have more limited economic opportunities and resources. Systemic patterns of child marriage can also perpetuate intergenerational cycles of poverty and poor development outcomes. ${ }^{31}$

Efforts to reduce harmful practices have often included life-skills and self-esteem building among women. Additionally, community-level activities have helped to reveal underlying causes of harmful practices and provided realistic ways to change them. These activities have also helped communities create accountability measures to establish new culturally accepted practices that are no longer harmful. ${ }^{32}$ Successful child marriage interventions, for instance, seek to delay marriage among adolescent girls by educating and supporting girls, building their life-skills, and engaging their community. ${ }^{33}$ To address female genital mutilation/cutting (FGM/C), the Tostan Community Based Education Program in Senegal, for example, included community dialogue, health education, skill building activities, promotion of positive interactions between men and women, performances, and mass media activities. Women and girls were able to openly share their feelings about FGM/C in a community forum. The program promoted dialogue between women and men about FGM/C, as well as other health issues such as family planning. This multipronged intervention decreased the practice of FGM/C among girls, increased support for girls to attend school, increased awareness of women's rights, and changed attitudes toward FGM/C and early marriage. Following these activities, community accountability mechanisms were put in place, including a public denouncement of FGM/C and the development of a law that addressed FGM/C and that was supported by men. ${ }^{34}$ SBC interventions that focus on ending harmful practices aim to improve equity in the household, increase partner communication, and discuss and challenge social constructions of gender and the interactions that drive these behaviors. ${ }^{15}$

\section{Ensure community involvement and accountability for promotion of gender equality}

SBC approaches that engage and mobilize communities can integrate gender at multiple levels (e.g., couples, families), and with service providers (e.g., communityand facility-based health workers, agriculture extension workers) to shift norms and hold everyone accountable. Although community engagement is often a feature of SBC programs, specific mechanisms for mobilizing the communities and building social accountability are not always an explicit component. ${ }^{35}$ Previous research has shown that addressing entrenched social and gender norms requires careful, strategic participation of key community members, including religious leaders and parents. For example, an adolescent SRH project in India faced reluctance from parents to expose adolescent girls to sexual health information until community mobilization was incorporated. ${ }^{36}$ Community commitment to shift inequitable norms can ensure that men and women are supported and accepted equally, contributing to more sustainable gender transformative SBC outcomes. ${ }^{37}$

Approaches to ensure community involvement and accountability to promote gender equality include identifying key male and female influencers and promoting them as change agents for shifting gender norms, encouraging community dialogues with equitable participation that address entrenched gender norms, and working with the identified change agents to build social accountability mechanisms and reduce disparities. Community dialogue around entrenched gender norms is also important in SBC strategies for promotion of gender equality and have included neighborhood meetings, performances, community education sessions, support groups, and mass media activities. ${ }^{23}$ The Tchova Tchova Project in Mozambique addressed inequitable gender norms to reduce HIV-related risk behaviors by using a community dialogue approach. The program included two main components-facilitated community dialogues and a radio magazine with profiles of men, women, and couples who transcended pervasive barriers (e.g., domestic violence, subordination of women) to make positive change. Evaluation of the program found that it was 


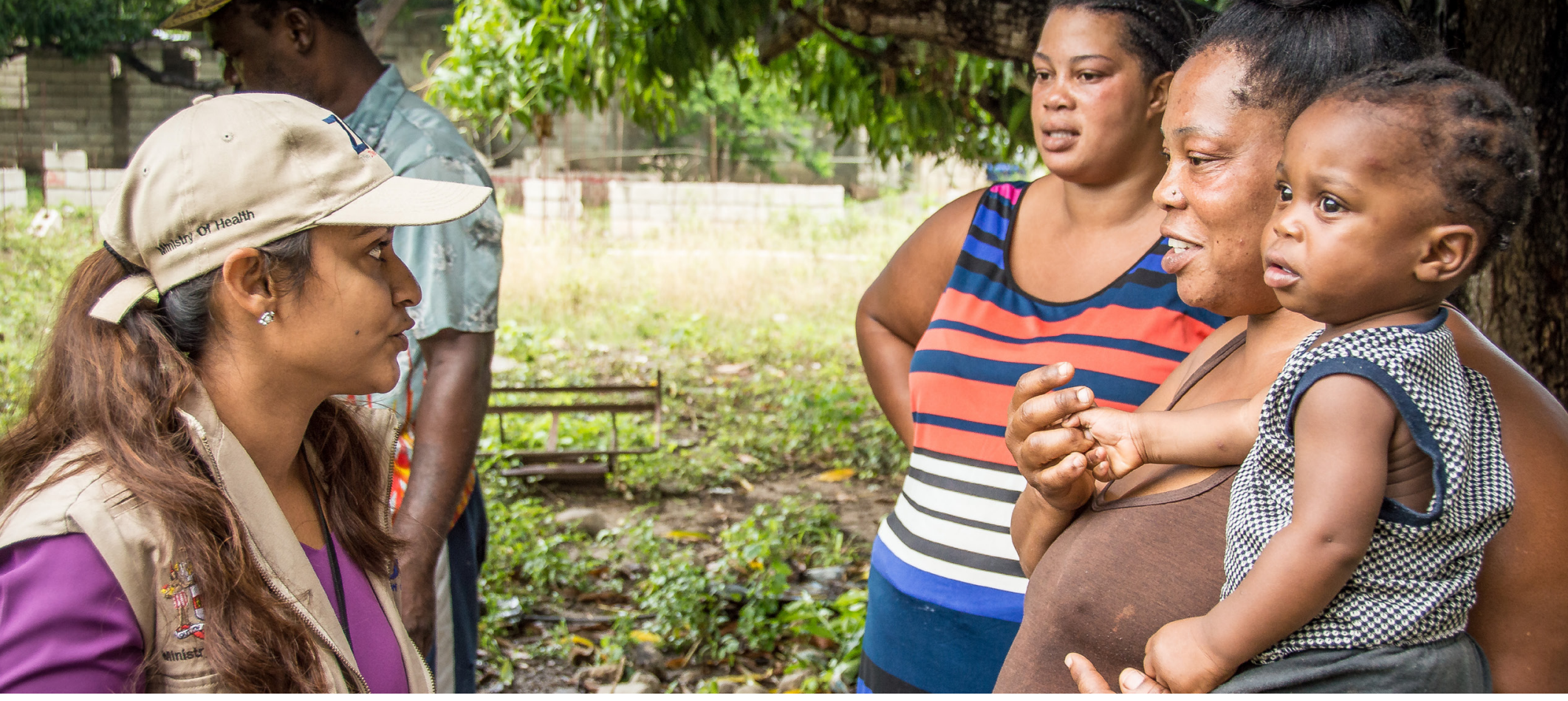

successful in shifting gender attitudes, gender roles, and HIV stigma in addition to other HIV-related risk behaviors. ${ }^{38}$ Another example in Kenya focused on reducing the practice of FGM/C by engaging male and female adults and youth in reflection about the cultural practice of $\mathrm{FGM} / \mathrm{C}$, and how FGM/C violates girls' rights to health and integrity. Each gender and age group gained a better understanding of how FGM/C is harmful to communities and challenged prevalent gender norms. The project staff understood that a law or policy that prohibited the practice would not challenge the cultural or social reasons for $\mathrm{FGM} / \mathrm{C}$, and the practice would likely continue underground. The staff worked with women, men, and religious leaders to establish a new ritual for girls that maintained cultural and celebratory elements without FGM/C. This new ritual was accepted by the community and created social accountability mechanisms that led to the elimination of this harmful practice. ${ }^{7}$ These results suggest that community dialogues and other activities that empower and enable leadership among communities can provide opportunities for men and women to voice issues that would otherwise remain undiscussed and come up with solutions of benefit to the entire community. ${ }^{38}$

\section{Consider gender dimensions during emergency preparedness and response}

Women and girls and men and boys are often affected differently by emergency and crisis situations, including disease outbreaks, climate/natural disasters, and regional or political conflict. SBC programs and interventions play an important role to ensure timely and accurate information and resources meet men and women's needs and address their unique risks. For instance, social norms around women's role as caretakers, cultural norms around women's sexuality and fertility, or heightened sexual violence during times of conflict, often means that women may bear undue burden and risk during crisis situations. Additional challenges during crisis situations, such as limited mobility and limited access to resources, can further disempower and disadvantage the most vulnerable, especially women and girls. ${ }^{39}$

In dealing with evolving emergency and crisis contexts, SBC approaches often have to rapidly assess the impact of shocks/stressors and how gender norms/inequalities influence risks for women and girls and men and boys, and the differing factors that enable or constrain individuals' resiliency. ${ }^{40,41}$ This includes responding to potential second order impacts in emergency situations, like GBV (e.g., physical, sexual, emotional, financial abuse), food insecurity, and health care access. For example, during the Zika virus outbreak in 2015-2016 in Latin America and the Caribbean, USAID supported a rapid response in the region and employed a phased approach to address the particular burden faced by women and girls of reproductive age. ${ }^{42}$ The first phase included integrated Zika virus protocols to change provider practices and messaging within family planning, antenatal, and postnatal visits, and in community-based efforts. Second, this information was integrated with providers at all SRH and gynecological services. Lastly, the project incorporated screening and care during postnatal screenings and early 
well-child visits. This experience highlighted the importance of paying attention to the gendered implications of emerging threats and the need for adaptive approaches to adequately address gender-related behaviors and norms. Only with this attention can SBC approaches ensure equitable opportunities for all to benefit from recovery, mitigation, and resilience efforts. Ensuring women's representation in decision-making related to disaster risk management is key so that mitigation efforts are designed with multiple perspectives, respond more holistically to the needs of communities, and increase equitable access to resources. ${ }^{43}$ For instance, the Risk Management and Climate Change Adaptation Networks (GRIDES) in Peru operate in geographic contexts prone to floods and droughts coupled with conditions of poverty and inequality. Women engaged in these networks have an explicit role in "decision-making on disaster risk management and climate change adaptation issues, achieving greater equality in the representation and stronger empowerment, showing how climate change had affected their lives." ${ }^{\prime 4}$ Further, prior efforts demonstrate the need to build capacity of male and female leaders (e.g., in communities, non-governmental organizations, ministries) to respond to crises that impact women and girls and men and boys differently for a more gender equitable response in risk management programs.

\section{Account for the intersecting gendered vulnerabilities that influence health and development outcomes}

Women and girls and men and boys from all gender identities experience different intersecting vulnerabilities, such as varying access to economic resources, mobility, and technology. Effective economic participation, so that males and females are empowered to equally participate in their local economies and have equitable access to and control over resources, is important for improving individual and household-level socio-economic status and associated health and non-health outcomes. Yet, women and girls in many countries are far less likely than men to own or control key economic assets, such as housing, technology, livestock, and formal savings. For instance, female entrepreneurs in Cambodia contribute significantly to their communities and economies; yet, in order to do so, they have to overcome barriers in accessing finance, societal expectations around their roles in the home, and often have lower education levels in comparison to men. ${ }^{45}$ SBC programs and interventions need to consider the multiple layered factors that may influence individual knowledge, attitudes, and behaviors and differentially affect health and non-health outcomes.

Inequitable access to financial and other resources influences desired behavioral or development outcomes for men and women. For example, a study in Nigeria found that rural women's increased access to forest resources (e.g., fuel, firewood, and fruits) had a direct positive impact on their income, household food consumption, and expenditure on education. Programs designed to increase women's knowledge, enhance their participation in governance of sustainable natural resources, and engagement in economic production and benefit-sharing processes yield improved health and non-health outcomes for women and their families. ${ }^{46}$ Effective SBC programs can leverage partnerships with key stakeholders (e.g., government, organizations, and programs) to help address multiple vulnerabilities experienced by targeted populations. Partnering with programs that enable women to secure decent jobs, access resources, and influence public policies can be particularly useful. ${ }^{47}$ In Zambia, the Mumbwa project implemented the "pass on the gift" program that encouraged family ownership of livestock and established rules for transferring property. This ensured that women had access to livestock and other resources, building economic and environmental assets for rural women. ${ }^{43}$ Other initiatives include: capacity development programs for women to lead and grow enterprises; business services and networking opportunities; field trips to visit successful businesses run by women; and, peer, individual, and group mentoring. These programs also create cross-sectoral mechanisms to address systemic gendered inequalities across SBC programs in health and non-health sectors (e.g., task force on menstrual hygiene involving education, health, and water, sanitation and hygiene sectors).

\section{- Build organizational capacity and systems for gender integration using a continuous learning approach}

Organizations and institutions implementing SBC programs should undertake regular internal assessments to ensure that their capacity, practices, and policies 
effectively advance gender equality and apply learning for continuous improvement. For example, though women make up a larger percent of the global health workforce, they experience disparities in recognition, pay, and promotion opportunities. ${ }^{8}$ Organizations that successfully integrate gender approaches can have stronger gender-equitable policies (e.g., equal pay), gender-equitable work practices, leadership that demonstrates a commitment to gender equality, gender training for staff, equal representation across staff levels, and administrative accountability measures. ${ }^{48}$ Yet, much work still needs to be done to build organizational capacity and systems for gender integration.

Building organizational capacity for gender integration requires building staff capacity on gender transformative concepts, using participatory and interactive methods, with an emphasis on personal reflection and growth. Staff capacity-strengthening facilitates understanding of key concepts and better knowledge of requirements to support gender equality, which can improve the quality of a program and lead to better health and non-health outcomes. ${ }^{29}$ Important areas to include are: understanding gender issues and concepts; integrating gender throughout the program cycle; utilizing gender analysis and methods; managing gender issues in specific sectors or countries managing gender integration (such as dealing with resistance); adhering to donor requirements on gender; and developing gender-integrated proposals. In Mali, a maternal mortality prevention project focused on how social, gender, and power norms influenced project outcomes. ${ }^{49}$ The processes included critical reflection among project staff on these norms, in addition to dialogues with health care workers and community members related to these norms. Organizations/institutions also need to look internally to ensure adherence to a defined set of gendered standards that is included in programs (see Box 2). ${ }^{29,50}$ Additionally, there is a need to examine policies, such as management roles and responsibilities, and ensure adequate resources are in place to promote gender equality to positively disrupt social and cultural attitudes that diminish women's role as key decision-makers. Capacity building on gender integration is rarely seen as a one-off or stand-alone activity. The most successful approaches toward capacity strengthening around gender perspectives take a continuous learning approach, identifying leaders within organizations/ institutions that support and champion gender integration efforts, using local gender experts to help train/ retrain staff on contextually relevant gender dimensions, building support on how to apply gender throughout the program cycle, and establishing local learning networks.

\section{BOX 2: GUIDELINES FOR EXAMINING THE LEVEL OF GENDER INTEGRATION}

The report "Pursuing gender equality inside and out: Gender mainstreaming in international development organizations" provides guidelines for examining the level of gender integration in an organization's culture. The report recommends that work of the organization should be aligned with the following statements: ${ }^{48}$

- I recognize that gender equality is critical to achieve all of my organization's goals.

- I work to ensure that gender considerations, concerns, and experiences of women and men, girls and boys, are integral to the design, implementation, monitoring, and evaluation of all legislation, policies, and programs.

- I work to promote equality between women and men, girls and boys, in all of my organization's policies, programs, strategies, and interventions.

- I work to ensure that women and men equally participate in setting priorities and goals and in planning so that programs meet the priorities and needs of women and men, girls and boys.

- I analyze the potential positive and negative impact of all of our interventions in all areas on women and girls and men and boys.

- I require that gender analyses be conducted prior to making important decisions on goals, strategic plans, and resource allocations. 


\section{Conclusion}

Gender integration is critical in SBC programs and interventions across health and non-health sectors in order to shift behaviors of individuals, as well as the norms that underpin them. A gender lens in SBC programming requires intentional engagement of men and women, and boys and girls, from all gender identities, in a mutually reinforcing way. Additionally, SBC programs often must look beyond expected health and non-health outcomes to unpack and address underlying gendered vulnerabilities. Successful SBC programs integrate gender throughout the program cycle from assessment and design to implementation and monitoring and evaluation, and finally through knowledge sharing and uptake.

In the scan of documents, a substantial number of resources were found on gender integration and SBC (Box 3 ) in the peer-reviewed and gray literature explaining how gender inequality leads to disparities among health and non-health outcomes. However, more documentation and knowledge sharing of programs that have designed, implemented, monitored and evaluated gendered SBC approaches are needed. While different programs had a direct or indirect impact on health and non-health outcomes, there seemed to be a missed opportunity to learn from gender integration experiences across different sectors (e.g., health, emergency preparedness, education, agriculture, economic growth). In part, this may be due to some of the differences in terminology used to assess and report on gender integration in SBC programs and interventions across sectors. On the other hand, gender integration can sometimes be seen as more peripheral to a program's goals and objectives. As SBC programs and interventions aim to address knowledge, attitudes, practices, and norms-gender integration needs to be central to their approach.

Addressing gender inequality through gender integration needs concerted effort. The SBC community across sectors is well-poised to galvanize promising practices, such as the ones in this scoping report, and lessons learned more broadly. Critical to this will be donor investment and development partners' commitment to sharing evidence generated from their experiences. This scoping review provides an initial synthesis of promising practices for gender integration in SBC. Continued implementation and assessment of gender integration and a systematic synthesis examining program impact is warranted to further advance this effort in the SBC field.

\section{BOX 3: SELECT RESOURCES ON GENDER INTEGRATION AND MAINSTREAMING ON SBC}

- USAID/IGWG. The Gender Integration Continuum. Programmatic Guidance. ${ }^{51}$

- USAID/HC3. Gender and Social and Behavior Change Communication Implementation Kit. ${ }^{52}$

- United Nations Development Programme. Gender Mainstreaming in Practice: A Toolkit. ${ }^{13}$

- Land O' Lakes International Development. Integrating Gender throughout a Project's Life Cycle 2.0. A Guidance Document for International Development Organizations and Practitioners. ${ }^{29}$

- USAID/IGWG. Do's \& Don'ts for engaging men \& boys. ${ }^{17}$

- CORE Group. Enhancing Nutrition and Food Security during the First 1,000 Days through Gendersensitive Social and Behavior Change: A Technical Resource Guide. ${ }^{53}$

- The TOPS Program and CARE International. REALIZE: Social and behavioral change for gender equity and diversity. ${ }^{54}$

- PRB. Pursuing gender equality inside and out: Gender mainstreaming in international development organizations. ${ }^{48}$

- African Development Bank Group. Checklist for gender mainstreaming in governance programmes. ${ }^{55}$ 


\section{Appendix 1: Phases 1 and 2 Key Search Terms}

\begin{tabular}{|lll|}
\hline \multicolumn{1}{|c|}{ PHASE 1 } & & PHASE 2 \\
Gender mainstreaming & Gender mainstreaming & Gender \\
Development & Gender integration & Social and behavior change \\
Global health & Equality & Program evaluations \\
Equality & Equity & Evaluations \\
Equity & Gender perspectives & \\
Gender perspectives & Male involvement & \\
Gender integration & Male engagement & \\
Male involvement & Female participation & \\
Female participation & Female empowerment & \\
Female empowerment & Female agency & \\
Male empowerment & Disability & \\
Girls & Gender-based violence & \\
Boys & Adolescents \\
Youth & Rights \\
Adolescents & Girls \\
Gender & Boys \\
& Youth \\
& Global health \\
& Gender \\
& Development & \\
\hline
\end{tabular}




\section{References}

1. USAID. 2018. "Social and behavior change." https://www. usaid.gov/what-we-do/global-health/cross-cutting-areas/social-and-behavior-change.

2. Gupta, Jaya et al. 2019. "Mainstreaming gender into global health programming to improve women's health," Health Care for Women International 41: 476-488. doi: 10.1080/07399332.2019.1608209.

3. United Nations Development Programme. N.D. "UNDP support to the integration of gender equality across the SDGs including Goal 5." New York: UNDP. https://www.undp. org/content/dam/undp/library/SDGs/5_Gender_Equality_digital.pdf.

4. USAID, PACE, and IGWG. "The gender integration continuum," Presentation slides. Accessed 8 March 2020. https://www. igwg.org/wp-content/uploads/2017/05/Gender-Continuum-PowerPoint_final.pdf.

5. USAID Interagency Gender Working Group. 2017. The Gender Integration Continuum Training Session User's Guide. Washington, DC: Population Reference Bureau. https://www.igwg. org/wp-content/uploads/2017/12/17-418-GenderContTraining-2017-12-12-1633_FINAL.pdf.

6. Greene, Margaret E. and Andrew Levack. 2010. "Synchronizing gender strategies." Washington, DC: Interagency Gender Working Group. https://www.igwg.org/wp-content/uploads/2017/06/synchronizing-gender-strategies.pdf.

7. Bridge Project and USAID Interagency Gender Working Group (IGWG). 2009. "A manual for integrating gender into reproductive health and HIV programs: from commitment to action," 2nd edition. Washington, DC: Population Reference Bureau. https://www.igwg.org/wp-content/uploads/2017/04/ manualintegrgendr09_eng.pdf.

8. Vriesendorp, Sylvia et al. 2010. Health Systems in Action: an ehandbook for leaders and managers. Cambridge, MA: Management Sciences for Health. https://www.msh.org/ resources/health-systems-in-action-an-ehandbookfor-leaders-and-managers.

9. Hill, Catherine and Greg Scarborough. 2018. "IFAD's ASAP gender assessment and learning review."

10. Gibbs, Andrews et al. 2015. "Reconstructing masculinity? A qualitative evaluation of the Stepping Stones and Creating Futures interventions in urban informal settlements in South Africa," Culture, Health \& Sexuality 17(2): 208-22. doi: 10.1080/13691058.2014.966150.

11. Skevington, Suzanne M., Elena C. Sovetkina, and Fiona B. Gillison. 2013. "A systematic review to quantitatively evaluate 'Stepping Stones': a participatory community-based HIV/ AIDS prevention intervention," AIDS and Behavior 17(3): 1025-39. doi: 10.1007/s10461-012-0327-6.

12. Gay, Jill, Melanie Croce-Galis, Karen Hardee, and Amelia Peltz. 2017. "Creating a culture of evidence use: Using an innovative knowledge translation platform to inform HIV/AIDS programming for women and girls," Working paper. Washington, DC: Population Council, The Evidence Project.
13. United Nations Development Programme in the Kyrgyz Republic. 2014. Gender Mainstreaming in Practice: A toolkit-part I/ sectoral briefs. Bishkek, Kyrgyz Republic: UNDP. https:// www.kg.undp.org/content/kyrgyzstan/en/home/library/womens_empowerment/a-toolkit--gender-mainstreaming-in-practice.html.

14. Bartel, D. and M. Greene. 2018. "Involving everyone in gender equality by synchronizing gender strategies," Blog, 10 September. https://www.igwg.org/2018/09/involving-everyone-in-gender-equality-by-synchronizing-gender-strategies/.

15. World Health Organization. 2007. "Engaging men and boys in changing gender-based inequity in health: evidence from programme interventions." Geneva: World Health Organization. https://www.who.int/gender/documents/Engaging_men_boys.pdf.

16. Kaufman, Michael et al. 2014. "Engaging men, changing gender norms: directions for gender-transformative action," MenEngage-UNFPA Advocacy Brief. New York: UNFPA.

17. Pulerwitz, A., Gottert, M. Betron, and D. Shattuck on behalf of the Male Engagement Task Force. 2019. "Do's \& don'ts for engaging men \& boys." Washington, D.C.: USAID Inter-agency Gender Working Group (IGWG). https://www.igwg.org/ wp-content/uploads/2020/01/Male-Engagement_DosDonts_Final.pdf.

18. Torell, Elin et al. 2019. "Assessing the impacts of gender integration in Ghana's fisheries sector," Coastal Management 47(6): 507-526. doi: 10.1080/08920753.2019.1669098

19. UN Women. 2013. "Women's leadership and political participation," In Brief. New York: UN Women. https://www. unwomen.org/ /media/headquarters/attachments/ sections/library/publications/2013/12/un\%20womenlgthembriefuswebrev2\%20pdf.ashx.

20. Kerner, Brad et al. 2013. Mentor Training Curriculum: Using Mentors to Increase Positive Fatherhood Practices and Non-Violent Couple Communication with Newly Married Young Men. Washington, DC: Institute of Reproductive Health, Georgetown University. https://irh.org/resource-library/real-fathers-mentor-curricula/.

21. Sundstrom, Beth et al. 2018. "It's your place: Development and evaluation of an evidence-based bystander intervention campaign," Health Communication 33(9): 1141-50, doi: 10.1080/10410236.2017.1333561.

22. Stevanovic-Fenn, N. et al. 2019. "Engaging men for effective family planning through couple communication: An assessment of two MCSP couple communication approaches in Togo." Washington, DC: Population Council, Breakthrough RESEARCH. https://breakthroughactionandresearch. org/wp-content/uploads/2019/09/Engaging-men-for-effective-FP-Togo.pdf.

23. Feldman-Jacobs, C. and M. Yeakey. 2011. "A summary report of new evidence that gender perspectives improve reproductive health outcomes." Washington, DC: Population Reference Bureau. http://www.prb.org/igwg_media/summary-report-gender-perspectives.pdf. 
24. UNAIDS. 2017. "Reaching out to men and boys: addressing a blind spot in the response to HIV." Geneva: The Joint United Nations Programme on HIV/AIDS (UNAIDS). https://www. unaids.org/sites/default/files/media_asset/blind_spot_. en.pdf.

25. Maguiraga, F., K. Kampo, and K. Dandara Toure. 2013. "Qualitative analysis of social change related to pregnancy in Bankass, Mopti: Projet Espoir Pour La Santé de La Mere et Du Nouveau-Ne (PEMN)." Mali: Care USA and CARE International Mali.

26. Breakthrough RESEARCH. 2019. "Advancing provider behavior change programming," Research and Learning Agenda. Washington, DC: Population Council. http:// breakthroughactionandresearch.org/wp-content/uploads/2019/02/RLA-Provider-Behavior-Change.pdf.

27. Warren, Charlotte E. et al. 2017. "Sowing the seeds of transformative practice to actualize women's rights to respectful maternity care: Reflections from Kenya using the consolidated framework for implementation research," BMC Women's Health 17(1): 69. doi: 10.1186/s12905-017-0425-8.

28. Hay, Katherine et al. 2019. "Disrupting gender norms in health systems: Making the case for change," Lancet 393(10190): 2535-49. doi: 10.1016/S0140-6736(19)30648-8.

29. Land O' Lakes International Development. 2015. Integrating Gender throughout a Project's Life Cycle 2.0. A Guidance Document for International Development Organizations and Practitioners. Shoreview, MN: Land O' Lakes International Development. https://www.fsnnetwork.org/sites/ default/files/Integrating-Gender-throughout-a-Project-s-Life-Cycle-2.pdf.

30. Population Reference Bureau. 2010. "Gender-based violence: Impediment to reproductive health." Washington, DC: Population Reference Bureau. https://assets.prb.org/igwg_media/gbv-impediment-to-RH.pdf.

31. Mathur, Sanyukta, Margaret Greene, and Anju Malhotra. 2003. "Too young to wed: the lives, rights, and health of young married girls." Washington, DC: ICRW. https://www.icrw.org/ wp-content/uploads/2016/10/Too-Young-to-Wed-theLives-Rights-and-Health-of-Young-Married-Girls.pdf.

32. Evans, W. Douglas et al. 2019. "The Saleema Initiative in Sudan to abandon female genital mutilation: Outcomes and dose response effects," PLoS One 14(3): e0213380. doi: 10.1371/journal.pone.0213380.

33. Amin, Sajeda, J.S. Saha, and J.A. Ahmed. 2018. "Skills-building programs to reduce child marriage in Bangladesh: A randomized controlled trial," Journal of Adolescent Health 63(3): 293-300. doi: 10.1016/j.jadohealth.2018.05.013.

34. Diop, Nafissatou et al. 2004. "The Tostan Program: Evaluation of a community-based education program in Senegal." Dakar, Senegal: Population Council. doi: 10.31899/rh2.1002.

35. Igras, Susan et al. 2019. "Scaling-up norms-focused interventions for adolescent and youth sexual and reproductive health: Current practice and reflections for moving the field forward," Journal of Adolescent Health 64(4 Suppl): S10-S12. doi: 10.1016/j.jadohealth.2019.01.002

36. Pandey, Neelanjana et al. 2016. "Effects of the PRACHAR project's reproductive health training programme for adolescents: Findings from a longitudinal study." New Delhi: Population Council. doi: 10.31899/pgy9.1018.
37. Food and Agriculture Organization of the United Nations. 2010. "UN Joint Programmes integrating gender issues in food security, agriculture and rural development." Rome: Food and Agriculture Organization of the United Nations. http://www.fao.org/3/i1914e/i1914e00.pdf.

38. Figueroa, Maria Elena et al. 2016. "Effectiveness of community dialogue in changing gender and sexual norms for HIV prevention: Evaluation of the Tchova Tchova Program in Mozambique," Journal of Health Communication 21(5): 554-63. doi: 10.1080/10810730.2015.1114050.

39. UN Development Group (UNDG) Western and Central Africa. 2015. "Socio-economic impact of ebola virus disease in West African countries: A call for national and regional containment, recovery and prevention." Western and Central Africa: UNDG. http://ageconsearch.umn.edu/record/267635/ files/RDT\%20Report\%200n\%20Ebola_PrintReadyFile. pdf.

40. Koester, Diana et al. 2016. "How can donors improve their support to gender equality in fragile settings? Findings from OECD research," Gender \& Development 24(3): 353-373. doi: 10.1080/13552074.2016.1240907.

41. Nordehn, Caitlin and Deborah Rubin. 2018. "Gender and climate change synthesis of IDRC's support to climate change research." Canada: IDRC. https://idl-bnc-idrc.dspacedirect.org/bitstream/handle/10625/57515/IDL-57515. pdf?sequence $=2$ \&isAllowed $=y$.

42. Beare, Skye et al. 2019. "Rapid integration of Zika virus prevention within sexual and reproductive health services and beyond: Programmatic lessons from Latin America and the Caribbean," Global Health: Science and Practice 7(1): 116-27. doi: 10.9745/GHSP-D-18-00356.

43. Chineka, Jestina et al. 2019. "Gender mainstreaming: A lasting solution to disaster risk reduction," Jàmbá: Journal of Disaster Risk Studies 11(3): 723. doi: 10.4102/jamba.v11i3.723.

44. Arana, María Teresa, Alicia Quezada, and Rebecca Clements. 2016. "Gender approaches in climate compatible development: Lessons from Peru," Policy Brief. Climate and Development Knowledge Network.

45. Grant, Melita et al. 2019. "Rural piped-water enterprises in Cambodia: A pathway to women's empowerment?," Water 11(12): 2541. doi: 10.3390/w11122541.

46. Marin, Amanda Beaujon and Anne T. Kuriakose. 2017. "Gender and sustainable forest management: Entry points for design and implementation." Climate Investment Funds. https:// www.climateinvestmentfunds.org/sites/cif_enc/files/ knowledge-documents/gender_and_sustainable_forest_management.pdf.

47. UN Women. "Economic empowerment of women," In Brief (New York: UN Women, n.d.), https://www2.unwomen.org/ /media/headquarters/attachments/ sections/library/publications/2013/12/un\%20 women_ee-thematic-brief_us-web\% 20 pdf.ashx$? v=3 \& d=20141013 T 121456$.

48. Gilles, Kate. 2015. "Pursuing gender equality inside and out: Gender mainstreaming in international development organizations." Washington, D.C.: Population Reference Bureau. https://stage.prb.org/wp-content/uploads/2015/03/ gender-mainstreaming.pdf. 
49. Kuzara, Jennifer et al. 2018. "Addressing social and gender norms to improve uptake of maternal health services in Mali: A descriptive study of CARE's Project Hope for Mothers and Newborns (PEMN)," Culture, Health \& Sexuality 20(11): 1273-86. doi: 10.1080/13691058.2017.1421707.

50. Kreibich, Saskia, Margret-Luise Meyer, and Jutta Lorey-Wagner. 2017. "HIV/AIDS and gender risk assessment study for the Food and Nutrition Security Programme, Malawi." Lilongwe: GIZ Malawi. https://www.snrd-africa.net/wp-content/ uploads/2017/10/20170427_HIV-and-Gender-risk-studyfor-FNSP_FINAL.pdf.

51. IGWG. n.d. "Programmatic guidance," accessed 13 July 2020. https://www.igwg.org/training/programmatic-guidance/.

52. Health Communication Capacity Collaborative (HC3). "Integrating gender into social and behavior change communication," accessed 13 July 2020. https://sbccimplementationkits.org/gender/courses/gender-and-social-and-behavior-change-communication/.

53. Ivankovich, M.B. and T. Faramand. 2015. "Enhancing nutrition and food security during the first 1,000 days through gender-sensitive social and behavior change: A technical resource guide." Washington, D.C.: CORE Group. https:// coregroup.org/wp-content/uploads/media-backup/ documents/Resources/Tools/Gender_Sensitive_SBC_ Tech_Resource_Guide_Final.pdf.

54. The TOPS Program and CARE International. 2017. "REALIZE: Social and behavioral change for gender equity and diversity." Washington, DC: The TOPS Program. https://coregroup. org/wp-content/uploads/2017/09/REALIZE.pdf.

55. African Development Bank. 2009. "Checklist for gender mainstreaming in governance programmes." Accessed 24 May 2019. https://www.afdb.org/en/documents/document/checklist-for-gender-mainstreaming-in-governance-programmes-20012. 


\section{Population Council}

4301 Connecticut Ave., NW | Suite 280

Washington, DC 20008

+12022379400

breakthroughactionandresearch.org 